\title{
Não, Isso Não é Coisa pra Homem - Masculinidades e os Processos de Inclusão/Exclusão em uma Escola da Baixada Fluminense - RJ
}

\author{
No, This is Not a Man Thing - Masculinity and the Processes of \\ Inclusion/Exclusion in a School in the Baixada Fluminense - RJ
}

Leandro Teofilo de Brito

Universidade Estadual do Rio de Janeiro - Brasil teofilo.leandro@gmail.com

\section{José Guilherme de Oliveira Freitas}

Universidade Federal do Rio de Janeiro - Brasil jguilherm@uol.com.br

\section{Mônica Pereira dos Santos}

Universidade Federal do Rio de Janeiro - Brasil monicapes@gmail.com

\section{Resumen}

Esta pesquisa, de inspiração etnográfica, tem por objetivo compreender de que modo os processos de inclusão/exclusão se fazem presentes nas construções de masculinidades de alunos de turmas do ensino fundamental, em uma escola pública municipal de Nova Iguaçu, região da Baixada Fluminense, estado do Rio de Janeiro. A partir da análise dos dados encontrados no campo de pesquisa, constatamos que a modificação ou a construção de novas culturas de inclusão relacionadas às questões de gênero no espaço escolar, em especial ao reconhecimento de variadas e múltiplas formas de masculinidades, que se diferenciem de - e contestem - sua forma hegemônica, mostra-se como o principal fator de mudança e de combate aos processos de exclusões, influenciando políticas e práticas escolares na busca incansável e incessante pelo movimento da inclusão no contexto educacional.

Palavras-chave: Gênero; Masculinidades; Inclusão/Exclusão; Educação; Baixada Fluminense.

\begin{abstract}
This ethnographically-inspired research aims to understand how the processes of inclusion/exclusion are present in the constructions of masculinity in elementary school students, in a public school in Nova Iguaçu, in the Baixada Fluminense region of Rio de Janeiro. From the analysis of the data found in field search, we found that the modification or building of new cultures of inclusion related to gender issues within the school, particularly the recognition of varied and multiple forms of masculinity, that differ from - and challenge - its hegemonic form, appears as the main factor of change and combat against social exclusion processes, influencing school policies and practices in a tireless and unceasing search for the movement of inclusion in the educational context.
\end{abstract}

Keywords: Gender; Masculinity; Inclusion/Exclusion; Education; Baixada Fluminense. 


\section{Introdução}

Reconhecido como um dos maiores desafios da escola no nosso presente, a educação básica de qualidade por meio da inclusão escolar, na qual o respeito pelas diferenças culturais, sociais e individuais de cada educando deve ser garantido e colocado em prática configura-se como uma das grandes buscas contemporâneas no que tange à educação de uma maneira geral. Pautandose nestes princípios, o termo inclusão, muitas vezes direcionado somente a ações para a educação especial ou confundido com a integração de pessoas com deficiências, está inserido em um contexto mais amplo, devendo ser compreendido como um processo, reiterando princípios democráticos de participação social plena e visto como um movimento de luta em todas as áreas da vida humana (SANTOS, 2009).

O conceito de inclusão, em que este trabalho se apoia, é discutido a partir da relação dialética e complexa com o termo exclusão, sob uma característica dinâmica e indissociável, na qual os termos não podem ser considerados, nem compreendidos de forma separada. A inclusão ocorre justamente porque existem exclusões, não se constituindo como um fim em si mesmo. Aprofundaremos esta discussão ao longo do trabalho.

Neste contexto, considerando que a utilização do termo gênero objetiva designar as relações sociais entre os sexos, Scott (1995) afirma que o uso do conceito, durante determinado tempo, foi sinônimo de 'mulheres', principalmente nos trabalhos de cunho acadêmico, que visavam um maior reconhecimento político e busca de legitimidade para os estudos feministas, nos anos de 1980. Posteriormente, sugeriu-se que qualquer informação sobre as mulheres seria necessariamente informação também sobre os homens, onde um implicava o estudo do outro, e, desta forma, o termo gênero dissociou-se única e exclusivamente de 'estudos das mulheres', referindo-se também a questões sobre homens e à construção de masculinidades. Esses estudos problematizam questões de extrema importância e relevância no tocante ao reconhecimento das diferenças entre os sujeitos nas sociedades ocidentais, seja nas questões relacionais entre os próprios homens ou entre homens e mulheres.

Para Santos (2006), no contexto educacional, é muito comum atribuir aos sujeitos do sexo masculino toda uma mitologia comportamental, onde meninos devem apresentar-se como inquietos, curiosos, mal comportados, geralmente com notas baixas em português e sempre habilidosos nos esportes, ou seja, modelos essencialistas e hierarquizados associados ao significado de 'ser homem'. Quando os mesmos não se apresentam nestes padrões, que podemos associar a projetos de masculinidade hegemônica (CONNELL, 1995), possivelmente surgem as exclusões, pois se impõe papéis pré-estabelecidos para os homens nos grupos sociais, não se levando em conta as diferenças individuais dos sujeitos, que são inerentes ao sexo e à história de vida de cada um. O reconhecimento da existência de formas múltiplas e variadas de masculinidades na nossa sociedade, consequentemente refletindo-se no contexto educacional, se faz primordial na construção de processos de inclusão em educação associados às questões de gênero.

Desta forma, buscamos compreender a partir de uma pesquisa de inspiração etnográfica, no cotidiano de uma escola pública da região da Baixada Fluminense RJ, de que modo os processos de inclusão/exclusão se fazem presentes nas construções de masculinidades de alunos de turmas do ensino fundamental. Discutiremos em seguida, a compreensão e a amplitude do conceito de Inclusão em Educação, em que este trabalho se baseia. 


\section{Inclusão em Educação}

Compreende-se como Inclusão em Educação um processo teórico/prático que reconhece as diferenças e a diversidade no âmbito educacional, levando-se em conta que abordagens de inclusão relativas ao ensino e aprendizagem devem basear-se nessas diferenças existentes entre os sujeitos para propor mudanças profundas no contexto escolar. Racismo, sexismo, classismo, homofobia e deficientismo são alguns modelos de intolerância à diferença e abuso de poder, refletidos no ambiente escolar, que perpetuam desigualdades, promovendo barreiras à participação e à aprendizagem, e consequentemente promovendo formas de exclusão (BOOTH \& AINSCOW, 2002).

Como citamos anteriormente, os termos inclusão/exclusão são entendidos a partir de um processo dialético e complexo, o que significa considerar o dinamismo com que se configura, se constrói e se estabelece nas relações humanas a partir de variados significados, desde se referir a um determinado grupo de excluídos, onde haverá uma representação de esforços da sociedade para lutar contra a situação de exclusão, considerando neste caso um sentido mais estrito, ou como um movimento históricopolítico interminável, dentro de uma visão mais ampla (SANTOS, 2009).

Além das características dialética e complexa, os processos de inclusão/exclusão também apresentam três dimensões indissociáveis: a construção de culturas, desenvolvimento de políticas e orquestração de práticas de inclusão. Denomina-se esta como uma característica tridimensional dos processos de inclusão/exclusão. A construção de culturas se refere aos valores, concepções, crenças e justificativas que construímos e expressamos sobre dada questão, situação, pessoa, etc., representando aquilo que se acredita e que se considera. $\mathrm{O}$ desenvolvimento de políticas diz respeito aos planejamentos pedagógicos, projetos escolares, regras disciplinares, etc., em nível micro (institucional e pessoal) e macro, expressos a partir de leis, decretos, moções, dentre outros. A orquestração de práticas se refere às culturas e políticas colocadas em ação no fazer do nosso dia a dia, seja o fazer pedagógico, didático, pessoal, performático, etc.

Considerar as dimensões culturas, políticas e práticas de inclusão/exclusão em uma relação dialética e complexa uma com a outra, é pensar a inclusão em educação de forma omnilética. Santos (2013) designa como uma perspectiva omnilética de Inclusão em Educação um modo de explicar/conceber e ser ao mesmo tempo, um conceito de caráter tanto reflexivo, como contemplativo e aplicável às nossas práticas e ao nosso modo de ser. Significa compreender os processos de inclusão/exclusão de uma maneira ampla, como por exemplo, uma percepção totalizante e integralizadora de dado evento - citamos um fenômeno social - que compõe, em si mesmo, possibilidades de variações infinitas e nem sempre imediatamente perceptíveis, visíveis ou imagináveis, mas nem por isso ausentes ou impossíveis, pois seu caráter relacional, pertinente, referencial e participativo - no sentido de ser parte - torna aquilo que se percebe dele tanto sua parte quanto seu criador. Essa perspectiva objetiva reconfigurar nossa compreensão do ambiente escolar a partir da tentativa de visualizar o que escape ao binarismo, a uma visão polarizada, contemplar o que ainda não seja visível, o que ainda nos seja estranho, o que ainda não seja passível de imaginação em uma percepção inicial, mas que ali está como uma possibilidade.

De acordo com Santos (2013):

Em resumo, assumir uma perspectiva omnilética de análise significa pensar 
em termos de integralidade, dubiedade, complementaridade e transgressividade das dimensões culturas, políticas e práticas em relação e ao mesmo tempo dialética e complexa (p.26).

Os processos e mecanismos de inclusão/exclusão estão presentes em variadas instâncias de nossa sociedade, como classe, raça, etnia, gênero, sexualidade, dentre outras, e refletem-se na luta de grupos sociais segregados, oprimidos e excluídos pela garantia de seus direitos e reconhecimento social. Desta forma a Inclusão em Educação tem uma importância fundamental no sentido de reconhecimento das diferenças em sua pluralidade no contexto escolar, assim como das necessidades educacionais específicas apresentadas por alunos e alunas, no combate ou pelo menos na minimização das exclusões neste contexto.

Uma visão omnilética sobre questões relacionadas à construção de masculinidades no contexto escolar significa operar na lógica de desconstrução de categorias fixas e estáveis, partindo da ideia singular de masculinidade, como um modelo único, hegemônico e heteronormativo a ser seguido pelos sujeitos do sexo masculino, para um dinamismo que considera masculinidades, a partir de suas ambiguidades, subjetividades, multiplicidades e hibridismos. Aprofundaremos em seguida as principais vertentes teóricas sobre masculinidades nos estudos de gênero.

\section{Masculinidades nos estudos de gênero}

Para Silva (2007) os estudos que se debruçam na construção de masculinidades já são significativos e reconhecidos no campo das investigações de gênero, desmistificando uma associação muito comum que perdurou durante muito tempo: a 'análise de gênero' como sinônimo de 'estudo das mulheres'. Todavia, grande parte destes trabalhos continuam sendo desenvolvidos e permanecem pautados sob uma ótica feminista, segundo o autor.

Citamos os trabalhos de Connell (1995, 2003), dentre os principais, na produção teórica sobre homens e masculinidades, no contexto dos estudos de gênero e sexualidade nas ciências sociais e humanas. Connell (1995) afirma que: "a masculinidade é uma configuração de prática em torno da posição dos homens na estrutura das relações de gênero" (p. 188). Para a autora ${ }^{1}$ falar das estruturas das relações de gênero significa enfatizar algo além das interações entre homens e mulheres, significa o reconhecimento do gênero como uma estrutura ampla, que engloba a economia, o estado, a família, entre outras instâncias e o gênero como uma estrutura bem mais complexa, que abarca diferentes masculinidades produzidas num mesmo contexto social.

As relações de dominação, subordinação, e porque não falarmos também de exclusão, onde a chamada masculinidade hegemônica possui outros três tipos de masculinidades subordinada, cúmplice e marginalizada agrupadas ao seu redor, foi um esquema pensado por Connell (2003) para descrever os modelos hierarquizados de masculinidades nas sociedades ocidentais. A masculinidade hegemônica é aquela ligada à legitimidade do patriarcado, garantindo uma posição de dominância dos homens, subordinação das mulheres e das outras três masculinidades. A masculinidade subordinada refere-se aos homens homossexuais, subordinados e excluídos pelos homens heterossexuais e aos meninos, levando-se em consideração a subordinação e a exclusão por um homem heterossexual adulto. A masculinidade cúmplice diz respeito aos homens que não se enquadram no padrão hegemônico de masculinidade, mas que se beneficiam dos dividendos patriarcais obtidos pela 
masculinidade hegemônica. A masculinidade marginalizada está associada à dominação e exclusão em relação à raça, classe social e a grupos étnicos minoritários. Connell (Idem) também aponta que a relação de marginalização pode estar presente na masculinidade subordinada.

Mais atualmente, fazendo uma reavaliação do conceito de masculinidade hegemônica, Connell \& Messerschimidt (2013) afirmam que a combinação da pluralidade de masculinidades e a hierarquia entre elas, característica fundamental do conceito, deve ser mantida, pois: "padrões múltiplos de masculinidade têm sido identificados em muitos estudos, em uma variedade de países e em diferentes contextos institucionais e culturais" (p. 262). Alguns outros pontos, para os autores, podem ser rejeitados como o modelo muito simples das relações sociais no contexto da masculinidade hegemônica. De acordo com os mesmos, os traços psicológicos e ideias psicanalíticas na formulação inicial do modelo hegemônico de masculinidade, acabaram caindo numa configuração específica de traços (hipóteses), abrindo caminho para o tratamento da masculinidade hegemônica através de um caráter fixo. Desta forma, qualquer modelo essencialista das masculinidades e a abordagem de traços para compreensão do gênero devem ser transcendidos.

Sobre as reformulações do conceito, Connell \& Messerschimidt (Ibidem) apontam quatro grandes áreas: a hierarquia de gênero, trazendo essa compreensão para um contexto mais amplo, no qual os estudos sobre masculinidades serão direcionados para problemas em outros campos das ciências sociais, como a violência e os efeitos da globalização; a geografia das masculinidades, em que se busca uma estrutura analítica de masculinidades hegemônicas em nível local, regional e global, havendo ligações entre os níveis e ao mesmo tempo reconhecendo suas especificidades; incorporação social, na qual a masculinidade hegemônica está ligada à representação e uso dos corpos dos homens, devendo ser um ponto melhor teorizado nestes estudos; e por fim a dinâmica das masculinidades, que aponta para a construção e transformação das masculinidades ao longo do tempo.

No contexto educacional, a problemática das masculinidades, a partir das proposições de Raewyn Connell, também vem sendo discutida por pesquisadores/as que reconhecem a importância dessas questões na formação escolar de meninos e jovens.

Em pesquisa sobre gênero e desempenho escolar, Carvalho (2008) aponta algumas concepções das professoras participantes das investigações, pautadas em relação ao desinteresse dos meninos pelos estudos, pois segundo as mesmas, características como desleixo, descompromisso e desinteresse faziam parte da postura dos alunos com dificuldades de aprendizagem, percebida como mais rebelde e mais assertiva que a postura das meninas que apresentavam as mesmas dificuldades. A questão do 'capricho' em um caderno de um aluno, também foi um ponto levantado na pesquisa de Carvalho (Ibidem), na qual a professora classifica como um caso isolado e uma exceção um menino apresentar-se com seu material organizado, fazendo com que a mesma confundisse o seu caderno com o de uma menina. As características no comportamento dos meninos, pelas concepções das professoras, eram atribuídas a uma naturalização de características oriundas da masculinidade hegemônica, pautada em preceitos essencialistas da identidade de gênero masculina.

Silva Junior (2011) ao investigar representações de masculinidades em uma escola de determinada periferia urbana, destaca que o discurso dos jovens no ambiente escolar, esteve em grande parte 
pautado no modelo hegemônico e em uma valorização da heterossexualidade como norma, embora uma gama de masculinidades fossem construídas e se entrecruzavam no cotidiano da escola, em busca de afirmação: "[...] as masculinidades são construídas, onde cada adolescente fabrica seu corpo, realiza sua performance, se apresenta como um projeto a ser construído, buscando atender ou responder às expectativas criadas sobre o que é ser homem" (p. 57).

Nessa direção, Pereira (2008) enfatiza que a ideia construída de que o homem não é portador de sentimentos e emoções, sendo voltado apenas para pensar, raciocinar e questionar faz parte de um modelo de masculinidade que o imaginário social instituiu, mas que pode e deve ser modificado pela educação, uma arma importante de luta para o equilíbrio e igualdade de oportunidades sociais, incluindo neste contexto as questões de gênero e consequentemente a construção de novas masculinidades.

\section{A pesquisa de campo}

A pesquisa de campo, do tipo etnográfico (ANDRÉ, 2009), ocorreu em uma escola da rede municipal da cidade de Nova Iguaçu, Baixada Fluminense, região metropolitana do estado do Rio de Janeiro. A região da baixada fluminense, segundo dados do Instituto Brasileiro de Geografia e Estatística (IBGE${ }^{2}$ ) é composta por treze municípios: Belford Roxo, Duque de Caxias, Guapimirim, Itaguaí, Japeri, Magé, Mesquita, Nilópolis, Nova Iguaçu, Paracambi, Queimados, São João de Meriti e Seropédica.

A escola investigada é pertencente ao bairro de Vila de $\mathrm{Cava}^{3}$, que está a quatorze quilômetros do centro de Nova Iguaçu, sendo classificada como uma área pertencente à zona rural da região. Considerada a principal escola municipal do bairro no atendimento de alunos que cursam a Educação infantil, as séries iniciais do ensino fundamental $\left(1^{\circ}\right.$ ao $5^{\circ}$ ano) e a Educação de jovens e adultos, foi inaugurada no ano de 2001, contando com três turnos em funcionamento e 933 alunos no ano de 2012, período em que a pesquisa de campo foi realizada.

Nossa escolha pelos sujeitos da pesquisa se deu pelas turmas de $5^{\circ}$ ano do ensino fundamental. Paechter (2009) afirma que o currículo do ensino fundamental apresenta às crianças uma imagem do mundo e de seu lugar nele como homem e mulher, permitindo que elas construam identidades como aprendizes, em alinhamento ou em contraposição a essas imagens, além de que é na faixa de idade entre 11 e 12 anos que as mesmas encontram na escola o local principal para a construção de suas identidades de gênero, segundo a autora.

Em relação a técnicas de pesquisa, André (2009) designa a observação participante, a entrevista e a análise de documentos como as técnicas que tradicionalmente são associadas à etnografia. Utilizamos, especificamente nesta pesquisa, a observação participante, com uso de diário de campo para anotações, além de entrevistas dos tipos semiestruturada e informal.

Assim, apresentaremos e discutiremos alguns dados referentes à pesquisa sobre masculinidades e os processos de inclusão/exclusão no cotidiano escolar.

\section{Masculinidades e as aulas de artes}

No contexto da pesquisa, as aulas de Artes foram colocadas em discussão por alunos e alunas, quando se percebeu nas observações, certa resistência dos meninos ao participarem das atividades propostas. Destacamos a seguir um diálogo entre alunos, alunas e um dos pesquisadores:

${ }^{4}$ Se fosse pela gente, nós nem faríamos desenho [...]. (Aluno 1)

Teve um dia que a professora colocou 
um passarinho e tinha uma flor no meio e nenhum menino gostou (Aluno 2)

Flor não é coisa pra menino, então? (Pesquisador)

Não, isso não é coisa pra homem (Todos os meninos)

A tia também coloca desenho pra menino e pra menina (Aluna 1)

$O$ que vocês acham disso: colocar um desenho pra menino e outro pra menina? (Pesquisador)

Não tem como dar um desenho de menina pra menino fazer, não dá (Aluno 3)

Só uma vez que ela colocou dois bonecos, um menino e uma menina. Esse todo mundo podia pintar (Aluna 2)

A tia não pode colocar desenho de menina pra gente fazer, mas teve uma vez que ela colocou o desenho do Batman e ela (aponta para a Aluna 1) quis fazer, mas isso é desenho de menino (Aluno 1)

Levantamos neste caso as pressões sociais e culturais que recaem sobre os meninos, em relação a um comportamento masculino que tende a negar constantemente o que é associado ao feminino, pautado no modelo hegemônico de masculinidade, sob uma matriz heterossexual (BUTLER, 2010), influenciando seu comportamento e seu interesse por determinadas tarefas dentro da escola. Pode-se perceber nessas falas uma oposição dos alunos às tarefas das aulas de artes, onde os mesmos se contrapunham a fazer qualquer atividade que estivesse relacionada ao que o imaginário social considera feminino, como desenhos de flores e de um passarinho, citados no exemplo. Connell (2003) exalta que do ponto de vista da masculinidade hegemônica, a homossexualidade, classificada como masculinidade subordinada, mantém aproximação com a feminilidade e, desta forma a negação e o distanciamento do feminino são cruciais na afirmação de meninos como homens em qualquer contexto.

Outra questão a ser colocada é a generificação das disciplinas escolares. Paechter (2009) afirma que algumas disciplinas são fortemente marcadas como masculinas e femininas e, desta forma meninos e meninas apoiam-se nestas premissas, alinhando-se ou opondo-se às noções vigentes e normatizadoras de masculinidades e feminilidades, para direcionarem seus gostos e interesses pessoais pelas matérias e conteúdos escolares. A forma como isso ocorre varia conforme a imagem da disciplina, seus conteúdos e suas práticas. Neste caso, os meninos, sob o discurso da masculinidade hegemônica, mostram-se favoráveis ao que o senso comum reconhece como delicado e feminino, mostrando-se assim resistentes e desinteressados às atividades das aulas de artes. Culturas generificadas e consequentemente excludentes, em relação às disciplinas escolares tendem a reforçar não apenas a divisão entre meninos e meninas, mas o afastamento daqueles e daquelas que independente do gênero, apresentem afinidades direcionadas para determinadas disciplinas marcadas pela oposição entre masculino e feminino.

\section{Exclusão na prática do futebol}

Os meninos das turmas investigadas reuniam-se constantemente para jogar futebol ao final das aulas, especialmente quando saíam mais cedo. Até pelo fato de não haver aulas de educação física para as turmas de $5^{\circ}$ ano ${ }^{5}$, a direção da escola permitia o uso da quadra pelos meninos, quando já haviam sido liberados das aulas. Dentre os meninos que não apresentavam interesse em jogar futebol, citamos os alunos Sandro, Leonardo e Guilherme $^{6}$ que poderiam ser considerados os alunos mais assíduos e estudiosos de sua turma. Amigos também fora da escola, 
Sandro e Leonardo construíam suas masculinidades através dos estudos e do bom comportamento na escola, assim como Guilherme, que fora da escola era um pouco mais afastado dos dois. Sandro também era mais distante do restante dos meninos da turma, diferente de Leonardo e Guilherme que interagiam um pouco mais com os outros meninos da sala.

Sandro relata suas causas pessoais do não interesse pelo futebol:

Eu não gosto de jogar nada com bola. Sou até mais de ficar dentro de casa (Aluno Sandro).

Já Leonardo e Guilherme retratam situações de exclusões vivenciadas na escola ao tentarem jogar futebol com os meninos da turma:

Eu não gosto, porque já fui muito xingado na hora do futebol, por perder um gol na cara... tem muita gente marrenta que gosta de futebol. Eu jogava com eles depois da aula, mas depois desse dia não fui mais... (Aluno Leonardo).

Uma vez eu também fui jogar futebol aqui na escola e sem querer eu fiz gol contra, daí começaram a me xingar e quase me bateram... (Aluno Guilherme).

As culturas identificadas entre os meninos expressam uma rejeição pelo futebol: Sandro aponta apenas não gostar de esportes com bola, mas Guilherme e Leonardo retratam situações pessoais de exclusões vivenciadas durante os jogos que participaram com os outros meninos na escola. Nestes dois últimos casos, uma prática de exclusão gerou uma cultura de repúdio à atividade esportiva, em específico ao futebol. Dunning (1992) afirma que grande parte dos desportos são, em sua essência, competitivos, possibilitando assim a emergência da agressão, e no caso específico do futebol, assim como alguns outros esportes de confronto simulado, constituemse como áreas privilegiadas para uma expressão socialmente aceitável, ritualizada e de certa forma controlada em relação à violência física entre homens, fato constatado nos relatos dos alunos Leonardo e Guilherme.

Em estudo recente sobre os processos de inclusão/exclusão em aulas de uma turma masculina de educação física no ensino fundamental, Brito \& Santos (2013) apontaram que a masculinidade hegemônica fez-se predominante entre os meninos no espaço das aulas, através da competitividade exacerbada na prática do futebol:

A competitividade, como uma das características centrais desta forma dominante de masculinidade, mostrouse como o principal mecanismo gerador dos processos de inclusão/exclusão durante as observações, permeada pela valorização do domínio das habilidades físicas e motoras dos mais aptos para a prática do Futebol. De forma secundária, masculinidades cúmplices e subordinadas estiveram presentes entre os meninos durante as aulas, sendo visivelmente dominadas pela sua forma hegemônica (p. 243 - 244).

Paechter (2009) afirma que a prática de esportes contribui para a construção de identidades masculinas, onde vigor, força física e boa forma corporal classificam-se como valores simbólicos que representam culturalmente o que é ser homem. A autora aponta que meninos que se mostram resistentes à sua prática nas escolas, acabam sendo excluídos de comunidades de masculinidades dominantes e hegemônicas, configurando-se desta forma, quase que uma obrigação do sexo masculino em internalizar o esporte como um dever na sua formação: 
[...] a educação física e os esportes escolares não somente ensinam formas determinadas de ser um homem, mas também induzem os meninos a integrarem uma comunidade ampla de práticas de masculinidade nas quais, em virtude de sua performance relativa, alguns são dominantes e outros subordinados [...] (PAECHTER, 2009, p.137).

A cultura excludente, historicamente construída pelas práticas esportivas, na qual os mais aptos terão mais possibilidades de sucesso frente aos menos aptos, onde a violência masculina permeia e se justifica pela vitória a todo custo, acabam por afastar e excluir aqueles que não se adequam às normas instituídas pelo esporte competitivo. Situações como as descritas pelos alunos, permeadas por situações de exclusões, culminam na construção de culturas de rejeição e repúdio às práticas esportivas. Desta forma, teremos sempre meninos que não corresponderão ao modelo preestabelecido pela masculinidade hegemônica, que possui o apreço pelo esporte como algo naturalizado na construção de suas identidades, levando-se em consideração os mecanismos de exclusão associados ao esporte e à consolidação do modelo dominante - hegemônico - de masculinidade. Uma prática de exclusão, a partir de um jogo de futebol na escola, é capaz de gerar entre os sujeitos excluídos, uma cultura de desapreço e desprezo pela prática de esportes, podendo até ir além do espaço escolar, sendo levada para toda a vida.

\section{Sexualidade e masculinidades}

Apresentamos abaixo três relatos retirados do diário de campo ${ }^{7}$ :

Durante o recreio, na fila do refeitório, meninos brincavam de apertar o pênis $e$ o testículo uns dos outros. A funcionária de apoio, responsável pela limpeza, ao perceber a brincadeira indaga: "tem alguém que é bicha aqui nessa fila? Deixa a professora de vocês saber de uma coisa dessas...". Ignorando a bronca os meninos seguem com a brincadeira até perceberem a presença do pesquisador homem na observação da cena, quando logo em seguida pararam com a brincadeira, mostrando-se envergonhados (Diário de campo em 09/03/2012).

Durante a aula, o aluno Claudio, usando uma calça jeans bem justa, circula pela sala, e é repreendido pela professora: "Claudio você só está em pé para que todo mundo veja o seu bumbum grande nesta calça apertada, não é?". $O$ aluno ri e senta envergonhado. A professora fala para a turma: "o mundo realmente está ficando gay, porque só o que eu vejo são homens com calças justas e eu acho ridículo" (Diário de campo em 14/05/2012).

Na fila dos meninos, para voltar à sala de aula após o recreio, Gabriel recebe de Sandro uma massagem nas costas, em meio a uma brincadeira de sentir cócegas. Os outros meninos da turma que estão na fila percebem e começam a rir da situação. Sandro, sem graça, para a massagem imediatamente $e$ Gabriel afirma para os outros meninos que era só uma brincadeira. A turma volta em fila para sala com todos rindo e debochando dos dois alunos (Diário de campo em 28/05/2012).

Podemos perceber, assim, que qualquer indício de desvio da norma heterossexual estará suscetível a uma prática de exclusão, conforme se constatou nos três fragmentos apresentados. Seja na brincadeira 'subversiva' realizada pelos meninos durante o recreio, seja na linguagem sexista e homofóbica, apresentada pela professora sobre a calça de 
um aluno, ou nos risos e deboches dos alunos, frente a uma maior aproximação entre dois sujeitos masculinos, as representações de masculinidades encontram-se sob total atenção daqueles e daquelas que procuram mantê-la dentro de um padrão e de uma coerência, ajustados às noções de heteronormatividade, tão ressaltadas pela sociedade, de uma maneira geral.

Segundo Butler (2010):

[...] as normas regulatórias do "sexo" trabalham de uma forma performativa para constituir a materialidade dos corpos e, mais especificamente, para materializar o sexo do corpo, para materializar a diferença sexual a serviço da consolidação do imperativo heterossexual (p. 111).

Para Louro (2000), a produção da heterossexualidade masculina - pautada na masculinidade hegemônica - é acompanhada da rejeição à homossexualidade, havendo também, historicamente, uma articulação muito forte entre masculinidade e sexualidade, quando comparada ao gênero feminino, conforme constatado no primeiro e no terceiro relato. A homofobia funciona como um obstáculo a uma maior aproximação entre homens, como também aos gestos e comportamentos autorizados para um 'macho', fazendo com que meninos e homens sejam vigilantes e cautelosos nas suas ações e em suas relações entre pares.

A autora complementa:

Esse sentimento, experimentado por mulheres e homens, parece ser mais fortemente incutido na produção da identidade masculina. $\mathrm{Na}$ cultura brasileira, a manifestação de afetividade entre meninos e homens é alvo de uma vigilância muito mais intensa do que entre as meninas e mulheres. De modo especial, as expressões físicas de amizade e de afeto entre homens são controladas, quase impedidas, em muitas situações sociais (p. 81).

Tecendo um olhar omnilético sobre os relatos apresentados, percebe-se que há uma resistência nos meninos em apresentarem-se e apropriarem-se a todo o momento de características pertencentes à masculinidade hegemônica. Embora tenham consciência de que poderiam ser chamados à atenção, os alunos no primeiro excerto só param com a brincadeira após perceberem um olhar masculino sobre a atitude de apertarem o pênis e o testículo uns dos outros; no segundo excerto o uso da calça justa só é visto como algo 'problemático' quando a professora chama a atenção e expõe os seus valores sobre homens que usam calças justas; e por fim, na terceira situação apresentada, caso não houvesse a chacota dos outros alunos, a brincadeira de massagem e cócegas continuaria ocorrendo normalmente entre os dois meninos. Novas masculinidades, resistentes ao modelo hegemônico, manifestam-se a todo o momento, contestando a sua hierarquização e os mecanismos de exclusões impostos pela mesma.

A escola deveria ser um ambiente, no mínimo, inclusivo e acolhedor, e não um palco de discriminações e exclusões às diversidades apresentadas pelos alunos em suas expressões de identidades, em particular quando a sexualidade é colocada em evidência, como afirma Freitas (2009). Neste contexto, o autor também complementa:

No que diz respeito ao gênero, pensamos que seja essencial à vida humana que cada qual possa, sem constrangimentos ou medos, viver sua identidade de gênero, sem aniquilar suas subjetividades, nem limitar suas possibilidades ou tampouco escandalizar os hipócritas. É preciso, sim, que tenham o direito de ser e de se 
sentirem iguais, em valor como ser humano, nas sociedades em que vivem (p.171).

\section{Considerações finais}

As representações e construções de masculinidades entre os meninos das turmas investigadas, de acordo com os dados apresentados, estiveram a todo o momento, em suas expressões, influenciadas pelos processos de inclusão/exclusão. $O$ espaço escolar se mostra como uma das principais instâncias produtoras de identidades generificadas, e no tocante às masculinidades, como um local no qual a vigilância e a regulação se fazem presentes no intuito de manter o modelo hegemônico de masculinidade como o principal a ser seguido por meninos e jovens, ao firmarem-se como homens em nossa sociedade.

Acreditamos que a modificação ou a construção de novas culturas de inclusão relacionadas às questões de gênero no espaço escolar, em especial ao reconhecimento de diversas e múltiplas masculinidades, que se diferenciem de - e contestem - sua forma hegemônica, mostra-se como o principal fator de mudança e de combate aos processos de exclusões, influenciando políticas e práticas escolares na busca incansável e incessante pelo movimento, sempre dialético e complexo, da inclusão no contexto educacional.

1 Raewyn Connell é uma mulher transexual. Seus principais trabalhos, entre as décadas de 80 e início dos anos 2000, foram escritos pelo nome de Robert W. Connell.

\footnotetext{
2 Disponível em < http://www.ibge.gov.br/home > Acesso em: 13 de Outubro de 2013
}

3 O bairro de Vila de Cava situa-se na região leste do município de Nova Iguaçu, próximo ao limite com a divisa de Duque de Caxias, município também pertencente à Baixada Fluminense e localizado no entorno direto da tradicional Reserva Biológica Federal de Tinguá. É uma região que possui sérios problemas em saneamento básico e no investimento de políticas públicas em educação (VIÉGAS, 2006).

$4 \quad$ As falas dos sujeitos participantes da pesquisa serão destacadas do texto e apresentadas em itálico.

5 Havia uma carência de professores de educação física na escola investigada, durante o período da pesquisa.

6 Os nomes apresentados são fictícios preservando o anonimato dos sujeitos.

7 Os relatos retirados do diário de campo estão descritos com as datas referentes ao dia da observação.

\section{Referências}

ANDRÉ, Marli Elisa. A etnografia da prática escolar. $16^{\mathrm{a}}$ ed. Campinas: Papirus, 2009.

BOOTH, Tony; AINSCOW, Mel. Index Para a Inclusão: Desenvolvendo a aprendizagem e a participação na escola. Traduzido por: Mônica Pereira dos Santos. Produzido pelo LaPEADE, 2002.

BRITO, Leandro Teofilo de; SANTOS, Mônica Pereira dos. Masculinidades na Educação Física escolar: um estudo sobre os processos de inclusão/exclusão. Revista Brasileira de Educação Física e Esporte, v. 27, n.2, p. 235-246, 2013.

BUTLER, Judith. Problemas de Gênero: feminismo e subversão de identidade. $3^{\mathrm{a}} \mathrm{ed}$. Rio de Janeiro: Civilização Brasileira, 2010

CARVALHO, Marília Pinto de. Gênero na sala de aula: a questão do desempenho escolar. In: MOREIRA, Antônio Flávio Barbosa; CANDAU, Vera Maria (Orgs.). Multiculturalismo: Diferenças Culturais e 
Práticas Pedagógicas. $2^{\mathrm{a}}$ ed. Petrópolis, RJ: Editora Vozes, 2008, p. 90-125.

CONNELL, Robert. Políticas da masculinidade. Educação e Realidade, Porto Alegre, v. 20, n. 2, p. 185-206. jul./dez., 1995.

CONNELL, Robert. Masculinidades. México: UNAM-PUEG, 2003.

CONNELL, Raewyn.; MESSERSCHIMIDT, James W. Masculinidade hegemônica: repensando o conceito. Revista Estudos Feministas, Florianópolis, v. 21, n.1, p. 241280, janeiro-abril/2013.

DUNNING, Erik. O desporto como área masculina reservada: notas sobre os fundamentos sociais da identidade masculina e as suas transformações. In: ELIAS, Norbert. (Org.). A busca da excitação. Lisboa: Diefel, 1992, p. 389-412.

FREITAS, José Guilherme de Oliveira. Inclusão e Gênero. In: SANTOS, Mônica Pereira dos; FONSECA, Michele Pereira de Souza da; MELO, Sandra Cordeiro de. (Orgs.). Inclusão em Educação: diferentes interfaces. Curitiba: Editora CRV, 2009, p. 145-172.

LOURO, Guacira Lopes. Currículo, gênero e sexualidade. Porto: Editora Porto, 2000.

PAECHTER, Carrie. Meninos e Meninas: aprendendo sobre masculinidades e feminidades. Porto Alegre: Artmed, 2009.

PEREIRA, Erik Giuseppe Barbosa. Discutindo gênero, corpo e masculinidade. In: ROMERO, Elaine; PEREIRA, Erik Giuseppe Barbosa (Org.). Universo do corpo: masculinidades e feminilidades. Rio de Janeiro: Shape, 2008, p. 87-102.

SANTOS, Mônica Pereira dos. Dialogando sobre inclusão em educação: contando casos (e descasos). Curitiba: Editora CRV, 2013.

SANTOS, Mônica Pereira dos. Inclusão pela educação: gênero, etnia e juventude. In: MELO, Vítor; TAVARES, Carla (Orgs.). O Exercício Reflexivo do Movimento: educação física, lazer e inclusão social. Rio de Janeiro: Shape. 2006, p. 226-240.

SANTOS, Mônica Pereira dos. Inclusão. In: SANTOS, Mônica Pereira dos; FONSECA, Michele Pereira de Souza da; MELO, Sandra Cordeiro de. (Org.). Inclusão em Educação: diferentes interfaces. Curitiba: Editora CRV, 2009, p. 9-21.

SCOTT, Joan. Gênero: uma categoria útil de análise histórica. Educação e Realidade, Porto Alegre, v. 20, n. 2, p. 71-99, julho/dezembro, 1995.

SILVA JUNIOR, Paulo Melgaço da. A construção social das masculinidades no ambiente escolar: uma visão de masculinidades possíveis nas periferias urbanas. Revista Sensus, v.1, n2, p. 47-59, 2011.

SILVA, Tomaz Tadeu da. Documentos de identidade: uma introdução às teorias do currículo. $2^{\mathrm{a}}$. ed. $11^{\mathrm{a}}$ reimpressão. Belo Horizonte: Autêntica, 2007.

VIÉGAS, Rodrigo Nuñez. Desigualdade Ambiental e Zonas de Sacrifício. Rio de Janeiro: FASE/IPPUR, 2006.

Recebido em 25 de novembro de 2013. Aceito em 09 de fevereiro de 2014. 